\title{
Dietary carbohydrate intake and cardio-metabolic risk factors in type 1 diabetes
}

\author{
Aila J. Ahola ${ }^{a, b, c}$, Carol Forsblom ${ }^{a, b, c}$, Valma Harjutsalo ${ }^{a, b, c, d}$, Per-Henrik Groop ${ }^{a, b, c, e, *}$, \\ on behalf of the FinnDiane Study Group \\ ${ }^{a}$ Folkhälsan Institute of Genetics, Folkhälsan Research Center, Helsinki, Finland \\ ${ }^{\mathrm{b}}$ Abdominal Center Nephrology, University of Helsinki and Helsinki University Central Hospital, Helsinki, Finland \\ ${ }^{\mathrm{c}}$ Research Program for Clinical and Molecular Metabolism, Faculty of Medicine, University of Helsinki, Finland \\ ${ }^{\mathrm{d}}$ Chronic Disease Prevention Unit, National Institute for Health and Welfare, Helsinki, Finland \\ e Department of Diabetes, Central Clinical School, Monash University, Melbourne, Victoria, Australia
}

\section{A R T I C L E I N F O}

Article history:

Received 18 June 2019

Received in revised form

13 August 2019

Accepted 14 August 2019

Available online 16 August 2019

Keywords:

Cardio-metabolic risk factors

Glycaemic control

Low-carbohydrate diet

Type 1 diabetes

\begin{abstract}
A B S T R A C T
Aims: Low-carbohydrate diet (LCD) has gained interest among individuals with diabetes as a means to manage glycaemia. We investigated the adherence to LCD in the Finnish Diabetic Nephropathy Study and whether carbohydrate restriction is associated with cardio-metabolic risk factors.

Methods: Cross-sectional data were available from 902 individuals with type 1 diabetes (44\% men, age $47 \pm 13$ years). Dietary data were collected twice with a 3-day diet record. Mean of the measurements was used. Carbohydrate intake $<130$ g/day or $<26 \mathrm{E} \%$ was used as indication of LCD. Individuals reporting LCD were compared to sex-, diabetes duration- and eGFR-matched controls with higher carbohydrate intakes ( $>253 \mathrm{~g} /$ day or $>48 \mathrm{E} \%$ ). In the whole population, carbohydrate-to-fat ratio was calculated and its association with health variables was investigated.

Results: Higher carbohydrate-to-fat ratio was associated with higher blood glucose variability, higher blood pressure, lower HDL cholesterol concentration, and in men with lower waist-to-hip ratio. LCD adherence $(n=69)$ was associated with lower BMI (25.6 vs. $\left.27.8 \mathrm{~kg} / \mathrm{m}^{2}, \quad \mathrm{p}=0.030\right)$, lower variability of blood glucose measurements (0.38 vs. $0.45 \mathrm{mmol} / \mathrm{l}, \mathrm{p}=0.030$ ), and lower diastolic blood pressure (74 vs. $79 \mathrm{mmHg}, \mathrm{p}=0.048$ ). Men reporting LCD had higher total (5.1 vs. $4.0 \mathrm{mmol} / \mathrm{l}, \mathrm{p}=0.007$ ) and non-HDL cholesterol ( 3.4 vs. $2.7 \mathrm{mmol} / \mathrm{l}, \mathrm{p}=0.021$ ). Women with LCD had higher HDL-cholesterol concentration (1.9 vs. $1.5 \mathrm{mmol} / \mathrm{l}, \mathrm{p}=0.014$ ).

Conclusions: Reduced blood glucose variability, related to LCD, could have clinical relevance to individuals with type 1 diabetes.
\end{abstract}

(c) 2019 Elsevier B.V. All rights reserved.

\footnotetext{
* Corresponding author at: Folkhälsan Research Center, Biomedicum Helsinki C318b, PO Box 63, FI-00014 University of Helsinki, Finland.

E-mail address: per-henrik.groop@helsinki.i (P.-H. Groop). 


\section{Introduction}

Prior to the discovery of insulin, dietary carbohydrate restriction was used as a method to manage blood glucose levels in type 1 diabetes [1]. After the exogenous insulin became available, however, diets with carbohydrates as the predominant macronutrient, became the standard of nutritional management. While today, recommending a particular macronutrient distribution is no longer officially enforced [2], carbohydrates persistently continue to provide the majority of dietary energy in the diets of individuals with type 1 diabetes $[3,4]$. Importantly, dietary carbohydrates contribute to postprandial glycaemia, which is a major determinant of, not only long-term glycaemia [5], but also of macrovascular complications and mortality [6].

Carbohydrate counting and subsequent dosing of bolus insulin, as taught in various education programmes such as the Dose adjustment for normal eating (DAFNE) [7], are the foundations of the modern nutritional management of type 1 diabetes. However, due to errors in estimating carbohydrate contents of the meals [8], and variation in the absorption of the injected insulin [9], reaching postprandial normoglycaemia is often a challenge [10]. It is therefore not surprising that suboptimal $\mathrm{HbA}_{1 \mathrm{c}}$ levels are frequently reported among individuals with type 1 diabetes [11].

Because of dissatisfaction with suboptimal glycaemic control related to the adherence to higher carbohydrate diets, some individuals with diabetes have once again turned to carbohydrate restriction as a means to tackle glycaemia. While most of the current observations have been from patients with type 2 diabetes [12], also individuals with type 1 diabetes may benefit from carbohydrate restriction as an adjunct to insulin treatment. Unlike seen in the Diabetes Control and Complications Trial where reduction in $\mathrm{HbA}_{1 \mathrm{c}}$, that followed the intensification of insulin therapy, was burdened by concomitant increase in the risk of hypoglycaemia [13], such risk has not been associated with improved glycaemia achieved by carbohydrate restriction [14-16]. Instead, restricting dietary carbohydrate intake has rather lead to lower variability in the blood glucose levels $[15,16]$.

Presuming unchanged energy requirement, reduction in carbohydrate intake needs to be accompanied by an increase in the intake of at least one other macronutrient. In practice, this is often fat [17], as protein requirement mainly depends on the urinary and faecal nitrogen loss, and protein required for tissue growth [18]. This has raised concerns whether adherence to such a high-fat diet would have negative consequences for cardio-metabolic risk factors [19-21]. This study was undertaken to explore the frequency of adhering to low-carbohydrate diets in a sample of Finnish individuals with type 1 diabetes. Additionally, our goal was to investigate the association between low-carbohydrate diet and cardiovascular risk factors.

\section{Methods}

The study subjects, in this cross-sectional study, were participants in the nation-wide multicentre Finnish Diabetic Nephropathy (FinnDiane) Study. The aim of the FinnDiane
Study is to identify risk factors for diabetes complications in adult ( $\geq 18$ years) individuals with type 1 diabetes. Participants were recruited from over 80 centres around Finland (see the electronic supplementary material for a list of the centres). Type 1 diabetes was defined as diabetes onset before the age of 40 years, and permanent insulin treatment, initiated within a year from the diagnosis. Of the FinnDiane Study participants, we included in the current analyses those who had completed a diet record for a minimum of 3 days with plausible energy intake [5020-14,600 kJ/d (1200-3500 kcal/d)], whose estimated glomerular filtration rate (eGFR) was $\geq 60 \mathrm{ml} / \mathrm{min} / 1.73 \mathrm{~m}^{2}$, and who showed no signs of acute infection (high-sensitivity C-reactive protein, hsCRP, $\leq 10 \mathrm{mg} / \mathrm{l}$ ). The Ethics Committee of The Helsinki and Uusimaa Hospital District approved the study protocol. The study was performed in accordance with the ethical standards laid down in the 1964 Declaration of Helsinki and its later amendments. Written informed consent was obtained from all participants upon study entry.

\subsection{Variables and measurements}

At the study visit the participants were thoroughly investigated, as previously described [22]. In brief, the participants' weight and height were measured in light clothing without wearing shoes. Height was measured using a wall-mounted stadiometer. Waist and hip circumferences were measured using an inelastic tape measure. Waist circumference was measured at the midway between the lowest rib and iliac crest, while the hip circumference was measured with the subject standing with feet close together, around the widest portion with the tape measure parallel to the floor. Body mass index (BMI; weight in $\mathrm{kg} /$ height in $\mathrm{m}^{2}$ ), waist-to-hip ratio (waist circumference/hip circumference), and body adiposity index (BAI; [hip circumference in $\mathrm{cm} /$ height in $\mathrm{m}^{1.5}$ ] - 18) were calculated. Following a minimum of ten-minute rest, blood pressure was measured twice using a digital blood pressure monitor (Omron M6, OMRON Healthcare UK Ltd, Milton Keynes, UK). In case the two measurements differed by over $10 \mathrm{mmHg}$ a third measurement was conducted, in which case the two measurements closest to each others were used. Mean of the two measurements was used in the analyses. $\mathrm{HbA}_{1 \mathrm{c}}$ was measured locally using a standardized assay. Serum lipid, lipoprotein, and creatinine concentrations were centrally determined at the laboratory of the Helsinki University Hospital from early morning blood samples. As participants had type 1 diabetes, fasting was not required, but light breakfast was allowed to prevent or treat hypoglycaemia. The serum creatinine concentration was used to calculate eGFR [23]. Serum hsCRP concentration was measured by immunoassay (Modular analyzer, Roche, Indianapolis, USA). The attending physician recorded information on the participant's current medication use and diabetes complications on a standardized form. Acute myocardial infarction, coronary bypass, stroke, amputation, and peripheral vascular disease were coded as hard cardiovascular event. Retinal laser treatment was an indication of severe diabetic retinopathy. Insulin dose was self-reported. The method to obtain self-reported data on physical activity has previously been 
published [24]. In short, participants retrospectively reported the frequencies, average durations, and intensities of $21 \mathrm{com}$ mon leisure-time physical activities over the past 12 months. From these reports, we calculated the metabolic equivalent of task hours (METh) by multiplying the duration of the activity by the activity- and intensity-specific metabolic equivalent. The METh was treated as a continuous variable in the multivariable models.

\subsection{Dietary intake}

The methods to study dietary intake, in the FinnDiane Study, have previously been described [4]. Briefly, at the study visit participants were asked to complete a validated diet questionnaire [25]. Upon returning the questionnaire, participants were sent a 3-day diet record. The allocated 3 days covered two weekdays and one weekend day, and continuation of habitual dietary practices was emphasised. The recording was repeated after a 2-3 months' interval with the aim at obtaining a total of 6-day recording with some seasonal variation. AivoDiet software (version 2.0.2.3, AIVO, Turku, Finland) was used to calculate energy and nutrient contents of the participants' diets, as reported in the records. Mean nutrient intakes from either 3-day (if only available) or 6-day record were calculated. In the same record, participants also reported self-monitored blood glucose (SMBG) values. From these reports, mean and coefficient of variation (CV, standard deviation divided by mean) of the measured values were calculated for each participant.

For investigating the association between lowcarbohydrate intake and health, we took two separate approaches. First, in order to utilise the data from the whole population, we calculated a carbohydrate-to-fat ratio using the percentages of energy (E\%) derived from carbohydrates and fats. The higher the ratio, the higher the carbohydrate intake in relation to fat intake. This ratio was used as a continuous variable in the analyses. Second, based on the calculated carbohydrate intake, individuals with low carbohydrate intakes ( $<130 \mathrm{~g} /$ day or $<26 \mathrm{E} \%$, as described in the paper by Feinman et al. [17]) were identified. These individuals were compared to sex-, diabetes duration- and eGFR-matched controls, selected from a pool of participants in the highest quintiles of carbohydrate intakes ( $>253 \mathrm{~g} /$ day or $>48 \mathrm{E} \%$ ). This matching was done to ensure that the two populations would be as similar as possible, so that potential differences in these variables would not obscure the observations.

\subsection{Statistical analyses}

All analyses were conducted using IBM SPSS Statistics for Windows, Version 22.0 (IBM Corp, Armonk, NY, USA), and alpha value was set to $5 \%$ (two-tailed test). Means \pm standard deviations, medians (interquartile ranges), and frequencies (\%) were used to describe the study sample in normally distributed, non-normally distributed, and categorical observations, respectively. The between-group comparisons, in these respective variables, were conducted with independent samples t-test, Mann-Whitney $U$ test, and Chi-squared test. Multivariable generalized linear regression analysis was applied when investigating the association between carbohydrate intake (either the carbohydrate-to-fat ratio or the low-carbohydrate status) and the cardio-metabolic risk factors. Models were adjusted for a number of background variables (sex, diabetes duration, eGFR, insulin dose, physical activity, BMI), medication related to the given outcome, and a number of dietary variables (energy, alcohol, fibre) considered important for the outcomes of interest. Data from men and women were analysed together, except in case of variables with known sex differences (e.g. waist-to-hip ratio and cholesterol).

\section{Results}

Data were available from 902 individuals (44\% men; mean \pm standard deviation age $47 \pm 13$ years) (Table 1 ). The median BMI of the sample was $25.2 \mathrm{~kg} / \mathrm{m}^{2}$ and $\mathrm{HbA}_{1 \mathrm{c}} 63 \mathrm{mmol} / \mathrm{mol}$ (7.9\%). Mean ( $\min , \max$ ) daily carbohydrate intakes of the whole sample were $205 \mathrm{~g}(65 \mathrm{~g}, 482 \mathrm{~g})$ and $42 \mathrm{E} \%$ (17 E\%, $60 \mathrm{E}$

\section{Table 1 - Basic characteristics and cardio-metabolic risk} factors of the total study sample.

\begin{tabular}{|c|c|}
\hline & n 902 \\
\hline CHO-to-fat ratio & $1.17(0.95-1.46)$ \\
\hline Men (\%) & 44.1 \\
\hline Age (years) & $47 \pm 14$ \\
\hline Diabetes duration (years) & $28(18-39)$ \\
\hline Insulin dose (IU/kg) & $0.55(0.42-0.70)$ \\
\hline Retinopathy (\%) & 28.4 \\
\hline eGFR $\left(\mathrm{ml} / \mathrm{min} / 1.73 \mathrm{~m}^{2}\right)$ & $101(89-112)$ \\
\hline Hard CV event (\%) & 11.2 \\
\hline BMI $\left(\mathrm{kg} / \mathrm{m}^{2}\right)$ & $25.2(23.0-27.8)$ \\
\hline $\mathrm{HbA}_{1 \mathrm{c}}(\mathrm{mmol} / \mathrm{mol})$ & $63(55-71)$ \\
\hline $\mathrm{HbA}_{1 \mathrm{c}}(\%)$ & $7.9(7.2-8.6)$ \\
\hline SMBG mean & $8.0(6.8-9.3)$ \\
\hline SMBG CV & $0.42(0.34-0.49)$ \\
\hline SBP (mmHg) & 135 (124-149) \\
\hline DBP (mmHg) & $76(70-83)$ \\
\hline hsCRP (mg/l) & $1.1(0.5-2.3)$ \\
\hline Triglycerides (mmol/l) & $0.91(0.71-1.24)$ \\
\hline Men & n 398 \\
\hline WHR & $0.93(0.89-0.98)$ \\
\hline BAI & $23.5(21.7-25.9)$ \\
\hline Total CHOL (mmol/l) & $4.40(3.93-5.00)$ \\
\hline Non-HDL CHOL (mmol/l) & $2.90(2.43-3.45)$ \\
\hline HDL-CHOL (mmol/l) & $1.49(1.24-1.77)$ \\
\hline HDL3-CHOL (mmol/l) & $0.76(0.61-0.91)$ \\
\hline Women & $n 504$ \\
\hline WHR & $0.83(0.79-0.87)$ \\
\hline BAI & $28.6(25.7-32.1)$ \\
\hline Total CHOL (mmol/l) & $4.63(4.11-5.15)$ \\
\hline Non-HDL CHOL (mmol/l) & $2.87(2.40-3.33)$ \\
\hline HDL-CHOL (mmol/l) & $1.72(1.44-2.03)$ \\
\hline HDL3-CHOL (mmol/l) & $0.75(0.63-0.93)$ \\
\hline
\end{tabular}

Data are presented as median (interquartile range), frequency, or mean \pm standard deviation. CHO-to-fat ratio, calculated from percentages of energy derived from carbohydrates and fats; eGFR, estimated glomerular filtration rate; Hard CV event, hard cardiovascular event; SMBG, self-monitored blood glucose; CV, coefficient of variation; SBP, systolic blood pressure; DBP, diastolic blood pressure; hsCRP, high-sensitivity C-reactive protein; WHR, waistto-hip ratio; BAI, body adiposity index; CHOL, cholesterol. 
\%). Mean (min, $\max$ ) daily fat intakes of the total population

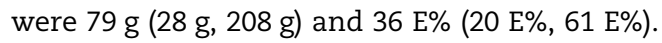

\subsection{Carbohydrate-to fat ratio}

Based on the percentages of energy derived from carbohydrates and fats, there was a median (interquartile range) carbohydrate-to-fat ratio of $1.17(0.95-1.46)$. In the multivariable analyses, higher carbohydrate-to-fat ratio was associated with higher variability of the SMBG, and higher systolic and diastolic blood pressure (Table 2). In men and women, higher carbohydrate-to-fat ratio was associated with lower HDL3-cholesterol concentration. In men, higher carbohydrate-to-fat ratio was additionally associated with a lower waist-to-hip ratio, while in women it was associated with lower total and HDL-cholesterol concentration. Dietary carbohydrate-to-fat ratio was not associated with BMI, body adiposity index, glycaemic control, or the concentrations of hsCRP, triglycerides, and non-HDL cholesterol.

\subsection{Low-carbohydrate intake us. higher carbohydrate intake}

Low-carbohydrate diet ( $<130 \mathrm{~g} /$ day or $<26 \mathrm{E} \%$ ) was endorsed by $69(7.6 \%)$ individuals. In all, 69 sex-, diabetes duration-, and eGFR-matched controls with higher carbohydrate intake were identified for the 69 individuals with low-carbohydrate diet (Table 3). These two groups were comparable with respect to age and complication status. Men with low carbohydrate intakes had higher WHR, total cholesterol concentration, non-HDL cholesterol concentration, and HDL3-cholesterol concentration compared to men with higher carbohydrate intakes. Women with lower carbohydrate intakes had lower BAI, and higher total, HDL-, and HDL3-cholesterol concentrations.

Those in the low-carbohydrate group reported lower total energy and fibre intake, but higher alcohol intake (Supplementary Table 1). Instead, protein intake per body weight was comparable between the two groups. In the multivariable analyses, individuals with lower carbohydrate intakes had lower BMI, lower variability of the SMBG values, and lower diastolic blood pressure (Table 4). Men in the lowcarbohydrate group had higher total and non-HDL cholesterol concentrations, while women had lower BAI and higher HDL-cholesterol concentration.

\section{Discussion}

Adherence to a low-carbohydrate diet was not common, in the current sample. Only $7.6 \%$ of the total population was considered low-carbohydrate adherents, with carbohydrate intakes below either $130 \mathrm{~g} /$ day or $26 \mathrm{E} \%$ [17]. Compared to sex-, diabetes duration-, and eGFR-matched individuals with higher carbohydrate intakes, those with low carbohydrate intake had significantly lower BMI, had lower variability of the SMBG values, and had lower diastolic blood pressure. In

Table 2 - The multivariable association between carbohydrate-to-fat ratio and cardio-metabolic risk factors.

\begin{tabular}{|c|c|c|c|}
\hline & B & 95\% Wald Confidence Interval & $P$ \\
\hline \multicolumn{4}{|l|}{ Men and women } \\
\hline Body mass index & -0.111 & $-0.867-0.645$ & 0.774 \\
\hline $\mathrm{HbA}_{1 \mathrm{c}}$ & 0.845 & $-1.623-3.313$ & 0.502 \\
\hline SMBG mean & 0.013 & $-0.345-0.370$ & 0.945 \\
\hline SMBG CV & 0.041 & $0.016-0.065$ & 0.001 \\
\hline Systolic blood pressure & 4.334 & $1.188-7.480$ & 0.007 \\
\hline Diastolic blood pressure & 2.471 & $0.725-4.217$ & 0.006 \\
\hline hsCRP & -0.110 & $-0.450-0.231$ & 0.528 \\
\hline Triglycerides & -0.052 & $-0.166-0.061$ & 0.368 \\
\hline \multicolumn{4}{|l|}{ Men } \\
\hline Waist-to-hip ratio & -0.024 & -0.046 to -0.002 & 0.029 \\
\hline Body adiposity index & 0.542 & $-0.358-1.442$ & 0.238 \\
\hline Total cholesterol & -0.168 & $-0.418-0.081$ & 0.186 \\
\hline Non-HDL cholesterol & -0.072 & $-0.313-0.169$ & 0.558 \\
\hline HDL-cholesterol & -0.082 & $-0.196-0.032$ & 0.158 \\
\hline HDL3-cholesterol & -0.067 & -0.126 to -0.009 & 0.023 \\
\hline \multicolumn{4}{|l|}{ Women } \\
\hline Waist-to-hip ratio & -0.007 & $-0.023-0.010$ & 0.416 \\
\hline Body adiposity index & 0.538 & $-0.746-1.822$ & 0.412 \\
\hline Total cholesterol & -0.255 & -0.476 to -0.034 & 0.024 \\
\hline Non-HDL cholesterol & -0.089 & $-0.290-0.112$ & 0.386 \\
\hline HDL-cholesterol & -0.144 & -0.262 to -0.027 & 0.016 \\
\hline HDL3-cholesterol & -0.121 & -0.181 to -0.060 & $<0.001$ \\
\hline \multicolumn{4}{|c|}{$\begin{array}{l}\text { SMBG, self-monitored blood glucose concentration; CV, coefficient of variation, hsCRP, high-sensitivity C-reactive protein. All models are } \\
\text { adjusted for sex, diabetes duration, eGFR, insulin dose, total energy intake, fibre intake, alcohol intake, and physical activity. HbA } \mathrm{A}_{1 \mathrm{c}} \text {, } \mathrm{SMBG} \\
\text { mean, SMBG CV, SBP, DBP, hsCRP, and triglyceride analyses are additionally adjusted for BMI. Moreover, lipid and hsCRP analyses are addi- } \\
\text { tionally adjusted for lipid lowering medication, and blood pressure analyses are additionally adjusted for antihypertensive medication. } \\
\text { Generalized linear regression. }\end{array}$} \\
\hline
\end{tabular}




\begin{tabular}{|c|c|c|c|}
\hline & $\begin{array}{l}\text { Low-CHO diet } \\
\text { n } 69\end{array}$ & $\begin{array}{l}\text { High-CHO diet } \\
\text { n } 69\end{array}$ & $P$ \\
\hline CHO-to-fat ratio & $0.75(0.60-0.91)$ & 1.59 (1.48-1.87) & $<0.001$ \\
\hline Men (\%) & 31.9 & 31.9 & 1.000 \\
\hline Age (years) & $51 \pm 11$ & $49 \pm 14$ & 0.262 \\
\hline Diabetes duration (years) & $35 \pm 14$ & $32 \pm 14$ & 0.325 \\
\hline Insulin dose (IU $/ \mathrm{kg})$ & $0.52(0.42-0.67)$ & $0.56(0.40-0.71)$ & 0.472 \\
\hline Retinopathy (\%) & 41.2 & 32.4 & 0.374 \\
\hline eGFR $\left(\mathrm{ml} / \mathrm{min} / 1.73 \mathrm{~m}^{2}\right)$ & $92 \pm 17$ & $96 \pm 15$ & 0.163 \\
\hline Hard CV event (\%) & 10.1 & 17.6 & 0.226 \\
\hline BMI $\left(\mathrm{kg} / \mathrm{m}^{2}\right)$ & $25.0(23.4-27.9)$ & $25.6(23.6-29.6)$ & 0.311 \\
\hline $\mathrm{HbA}_{1 \mathrm{c}}(\mathrm{mmol} / \mathrm{mol})$ & $60(53-72)$ & $65(55-72)$ & 0.208 \\
\hline $\mathrm{HbA}_{1 \mathrm{c}}(\%)$ & $7.6(7.0-8.7)$ & $8.1(7.2-8.7)$ & 0.208 \\
\hline SMBG mean (mmol/l) & $8.2(6.8-9.8)$ & $7.7(6.8-9.5)$ & 0.681 \\
\hline SMBG CV (mmol/l) & $0.39 \pm 0.13$ & $0.42 \pm 0.12$ & 0.138 \\
\hline $\mathrm{SBP}(\mathrm{mmHg})$ & $139(127-151)$ & $139(129-150)$ & 0.696 \\
\hline DBP (mmHg) & $75 \pm 9$ & $78 \pm 9$ & 0.101 \\
\hline hsCRP (mg/l) & $1.1(0.5-2.3)$ & $1.2(0.5-2.6)$ & 0.939 \\
\hline TG $(\mathrm{mmol} / \mathrm{l})$ & $0.95(0.69-1.25)$ & $0.97(0.68-1.30)$ & 0.995 \\
\hline Men & $n 22$ & $n 22$ & \\
\hline WHR & $0.96 \pm 0.07$ & $0.92 \pm 0.06$ & 0.040 \\
\hline BAI & $25.0 \pm 4.8$ & $24.1 \pm 2.9$ & 0.463 \\
\hline Total CHOL (mmol/l) & $4.79(3.99-5.27)$ & $4.27(3.76-4.64)$ & 0.010 \\
\hline Non-HDL CHOL (mmol/l) & $3.28 \pm 0.89$ & $2.79 \pm 0.44$ & 0.033 \\
\hline HDL-CHOL (mmol/l) & $1.71 \pm 0.57$ & $1.48 \pm 0.50$ & 0.163 \\
\hline HDL3-CHOL (mmol/l) & $0.91 \pm 0.26$ & $0.72 \pm 0.23$ & 0.022 \\
\hline Women & $n 46$ & $n 46$ & \\
\hline WHR & $0.85 \pm 0.06$ & $0.85 \pm 0.07$ & 0.962 \\
\hline BAI & $29.3 \pm 4.5$ & $32.3 \pm 5.4$ & 0.004 \\
\hline Total CHOL (mmol/l) & $4.89(4.49-5.51)$ & $4.46(3.84-4.88)$ & 0.002 \\
\hline Non-HDL CHOL (mmol/l) & $3.08 \pm 0.91$ & $2.89 \pm 0.68$ & 0.277 \\
\hline HDL-CHOL $(\mathrm{mmol} / \mathrm{l})$ & $1.96 \pm 0.56$ & $1.55 \pm 0.36$ & $<0.001$ \\
\hline HDL3-CHOL (mmol/l) & $0.86 \pm 0.23$ & $0.73 \pm 0.23$ & 0.009 \\
\hline
\end{tabular}

Data are presented as median (interquartile range), frequency, or mean \pm standard deviation. Low-CHO diet, low-carbohydrate diet, $<130 \mathrm{~g} /$ day or <26 E\%; High-CHO diet, higher carbohydrate diet, sex-, diabetes duration- and eGFR-matched controls identified from a pool of participants in the highest quintile of carbohydrate intake (>253 g/day or $>48 \mathrm{E} \%$ ); CHO-to-fat ratio, calculated from percentages of energy derived from carbohydrates and fats; eGFR, estimated glomerular filtration rate; Hard CV event, hard cardiovascular event; SMBG, self-monitored blood glucose concentration; CV, coefficient of variation; SBP, systolic blood pressure; DBP, diastolic blood pressure; hsCRP, high-sensitivity C-reactive protein; TG, triglycerides; WHR, waist-to-hip ratio; BAI, body adiposity index; CHOL, cholesterol.

women with lower carbohydrate intakes, lower BAI and higher HDL-cholesterol concentrations were observed, while in men low-carbohydrate diet was associated with higher total and non-HDL cholesterol levels. In the whole population, we investigated the association between dietary carbohydrate-to-fat ratio and cardio-metabolic risk factors. In these analyses, higher carbohydrate intake in relation to fat was associated with higher blood glucose variability and higher systolic and diastolic blood pressure, and lower HDL3-cholesterol concentrations. Furthermore, in men, higher carbohydrate-to-fat ratio was associated with lower waist-to-hip ratio, and in women it was associated with lower total and HDL-cholesterol concentrations.

The association between adherence to a low-carbohydrate diet and glycaemic control, in type 1 diabetes, has been reported in a number of previous papers. In an online survey including 316 children and adults with type 1 diabetes, who voluntarily adhered to a low-carbohydrate diet, an average $\mathrm{HbA}_{1 \mathrm{c}}$ of $39 \mathrm{mmol} / \mathrm{mol}$ (5.7\%) was reported [14]. This excep- tional glycaemic control was achieved with an average daily carbohydrate intake of $36 \pm 15 \mathrm{~g}$, without an increase in the frequency of hypoglycaemias. In another observational study, the mean $\mathrm{HbA}_{1 \mathrm{c}}$ of 11 adults with type 1 diabetes, following a diet with $<55 \mathrm{~g}$ of carbohydrates per day, was $35 \mathrm{mmol} / \mathrm{mol}$ (5.4\%) [21]. Nielsen et al described their observations from a total of 48 individuals with type 1 diabetes who took part in an educational course to reduce daily carbohydrate intake to $\leq 75 \mathrm{~g}$ per day [26]. Three months after the start of the course, a significant reduction in $\mathrm{HbA}_{1 \mathrm{c}}$ was reported. Moreover, unlike in those not adherent, a significant improvement in glycaemic control was evident among the continuously adherent participants also four years after the course. Randomized trials with low-carbohydrate diets in type 1 diabetes are scarce. In one small study, 10 subjects with type 1 diabetes were randomly assigned either to a standard carbohydrate counting course or to the same course with additional instructions to achieve and maintain a diet with a daily carbohydrate intake of 50-75 g [27]. At the end of the 12-week 


\begin{tabular}{|c|c|c|c|c|c|}
\hline & \multicolumn{2}{|c|}{ Low-CHO diet $n 69$} & \multicolumn{2}{|c|}{ High-CHO diet $n 69$} & \multirow[b]{2}{*}{$P$} \\
\hline & Mean & $95 \%$ CI & Mean & $95 \%$ CI & \\
\hline \multicolumn{6}{|l|}{ Men and women } \\
\hline BMI $\left(\mathrm{kg} / \mathrm{m}^{2}\right)$ & 25.6 & $24.1-26.8$ & 27.8 & $26.5-29.1$ & 0.030 \\
\hline $\mathrm{HbA}_{1 \mathrm{c}}(\mathrm{mmol} / \mathrm{mol})$ & 61.4 & $58.0-64.8$ & 64.6 & $60.8-68.3$ & 0.278 \\
\hline SMBG mean $(\mathrm{mmol} / \mathrm{l})$ & 8.3 & $7.7-8.8$ & 8.3 & 7.7-8.9 & 0.902 \\
\hline SMBG CV (mmol/l) & 0.38 & $0.34-0.42$ & 0.45 & $0.41-0.49$ & 0.030 \\
\hline SBP (mmHg) & 136 & $132-141$ & 142 & $137-147$ & 0.188 \\
\hline DBP (mmHg) & 74 & $72-77$ & 79 & $76-81$ & 0.048 \\
\hline hsCRP (mg/l) & 1.9 & $1.4-2.5$ & 1.9 & $1.3-2.5$ & 0.962 \\
\hline Triglycerides (mmol/l) & 1.18 & $1.02-1.34$ & 1.03 & $0.85-1.20$ & 0.277 \\
\hline \multicolumn{6}{|l|}{ Men } \\
\hline WHR & 0.95 & $0.93-0.98$ & 0.95 & $0.92-0.99$ & 0.969 \\
\hline BAI & 25.3 & $23.5-27.2$ & 24.9 & $22.4-27.4$ & 0.813 \\
\hline Total CHOL (mmol/l) & 5.08 & $4.68-5.48$ & 4.00 & $3.46-4.55$ & 0.007 \\
\hline Non-HDL CHOL (mmol/l) & 3.42 & $3.12-3.72$ & 2.71 & $2.26-3.15$ & 0.021 \\
\hline HDL-CHOL (mmol/l) & 1.67 & $1.46-1.88$ & 1.58 & $1.29-1.86$ & 0.658 \\
\hline HDL3-CHOL (mmol/l) & 0.89 & $0.80-0.98$ & 0.82 & $0.69-0.96$ & 0.500 \\
\hline \multicolumn{6}{|l|}{ Women } \\
\hline WHR & 0.85 & $0.82-0.87$ & 0.86 & $0.83-0.88$ & 0.692 \\
\hline BAI & 29.0 & $27.1-31.0$ & 33.1 & $31.1-35.2$ & 0.014 \\
\hline Total CHOL (mmol/l) & 4.90 & $4.57-5.23$ & 4.52 & $4.20-4.84$ & 0.162 \\
\hline Non-HDL CHOL (mmol/l) & 3.00 & $2.74-3.25$ & 3.03 & $2.77-3.28$ & 0.884 \\
\hline HDL-CHOL (mmol/l) & 1.91 & $1.73-2.10$ & 1.54 & $1.36-1.73$ & 0.014 \\
\hline HDL3-CHOL (mmol/l) & 0.85 & $0.76-0.94$ & 0.76 & $0.67-0.85$ & 0.199 \\
\hline \multicolumn{6}{|c|}{$\begin{array}{l}\text { Data are presented as adjusted means and standard errors. Low-CHO diet, low-carbohydrate diet, }<130 \text { g/day or }<26 \mathrm{E} \% \text {; High-CHO diet, higher } \\
\text { carbohydrate diet, sex-, diabetes duration- and eGFR-matched controls identified from a pool of participants in the highest quintile of car- } \\
\text { bohydrate intake ( }>253 \mathrm{~g} \text { /day or }>48 \mathrm{E} \%) \text {; SMBG, self-monitored blood glucose concentration; CV, coefficient of variation; SBP, systolic blood } \\
\text { pressure; DBP, diastolic blood pressure; hsCRP, high-sensitivity C-reactive protein; WHR, waist-to-hip ratio; BAI, body adiposity index; CHOL, } \\
\text { cholesterol. All models are adjusted for sex, diabetes duration, eGFR, insulin dose, total energy intake, fibre intake, alcohol intake, and physical } \\
\text { activity. } \mathrm{HbA}_{1 \mathrm{c}} \text {, SMBG mean, SMBG CV, SBP, DBP, hsCRP, and triglyceride analyses are additionally adjusted for BMI. Moreover, lipid and hsCRP } \\
\text { analyses are additionally adjusted for lipid lowering medication, and blood pressure analyses are additionally adjusted for antihypertensive } \\
\text { medication. Generalized linear regression. }\end{array}$} \\
\hline
\end{tabular}

intervention $\mathrm{HbA}_{1 \mathrm{c}}$, in the carbohydrate restriction group, was significantly reduced from a mean of 63 to $55 \mathrm{mmol} / \mathrm{mol}$ (7.9 to $7.2 \%$ ), with no change in the control group. Albeit weight loss was not promoted, in that study, a $6.3 \%$ and $0.5 \%$ weight reduction was observed in the intervention and control group, respectively. In the current study, we also looked at the relation between carbohydrate intake and a number of variables related to body weight. Here we noticed that individuals with higher carbohydrate intakes had higher BMI, and women with high carbohydrate intakes had higher BAI compared to those adhering to a lower carbohydrate diet. Contrary to these observations, higher carbohydrate intake in relation to fat was in men associated with lower waist-to-hip ratio. As carbohydrate restriction is sometimes used as a weight-loss method [28], our cross-sectional observations could indicate that carbohydrate restriction is more prevalent among men with a desire to lose weight.

Intensified insulin therapy, in the Diabetes Control and Complications Trial, resulted in improved glycaemic control, but was only accomplished by simultaneous increase in the risk of hypoglycaemia [13]. It has been suggested that improving glycaemic control without increasing the risk of hypoglycaemia may only be achieved by reducing glycaemic variability [29]. Of interest, adhering to a low-carbohydrate diet and diets with lower carbohydrate-to-fat ratio, in the current study, were associated with reduced variability in the blood glucose measurements. This could be of clinical importance as large blood glucose variability has been suggested to play a key role in the pathology of end-organ damage in diabetes [30]. Reduced glycaemic variability has also been reported in other studies of low-carbohydrate diets $[15,16,21]$. In addition to improved glycaemia and reduced glycaemic variability, low-carbohydrate diets have been associated with longer time spent in euglycaemia, and less time in hypoglycaemia [15].

Besides their effects on glycaemia, low-carbohydrate diets have also been associated with improved HDL-cholesterol levels $[14,25,28,31]$, lower triglyceride concentrations $[14,25,28,31]$, and reduced blood pressure [31]. The current observations with lower blood pressure and higher HDL-cholesterol concentration, associated with diets lower in carbohydrates in relation to fats, are in line with these reports. However, these beneficial effects are sometimes opposed by observations of increased total and/or LDL-cholesterol concentrations [14,21,31], which have raised concern of long-term safety of low-carbohydrate diets [21]. In the current study, higher total cholesterol and non-HDL cholesterol concentrations were observed in 22 men in the low-carbohydrate arm. Instead, in women, higher 
carbohydrate-to-fat ratio was associated with lower total cholesterol levels. However, this association seemed to be explained by lower HDL-cholesterol concentrations, instead of lower non-HDL cholesterol concentrations. In previous studies, high fat intake has shown to give rise to the largersized LDL-cholesterol particles, which are sometimes considered less atherogenic than the smaller and denser particles [32,33]. Larger LDL-cholesterol particles can, however, also be associated with increased coronary disease risk, particularly in the setting of normal or low triglyceride levels [32]. Longitudinal trials are, therefore, needed to assess the cardio-metabolic effects of low-carbohydrate diets.

Considering the low number and the small size of the published studies in this field, a large sample of well-defined individuals with type 1 diabetes is a major strength of the current study. However, there are also important limitations to be acknowledged. The study is cross-sectional, and can therefore only reveal associations between dietary intake and health variables. Despite considering a number of confounders in the analyses, residual confounding from variables not accounted for may remain. As participants were volunteers, some selection bias may also be evident. It is likely that individuals more interested in health and diet are overrepresented in the current sample. Due to the changes in cardiovascular risk factors and dietary intake related to emerging diabetic kidney disease, we excluded those with eGFR $<60 \mathrm{ml} / \mathrm{min} / 1.73 \mathrm{~m}^{2}$. Therefore, the current observations may only be generalized to individuals with type 1 diabetes and fairly well preserved renal function. The assessment of dietary intake with a self-reported record has its limitations, such as over- and under-reporting of food items generally considered healthy and unhealthy, respectively. Whether such misreporting would have affected the macronutrient proportions of the diets, is not known. While, with a $417 \mathrm{~g}$ (or $43 \mathrm{E} \%$ ) range, we were able to capture great diversity in the carbohydrate intake, the current results may only be applied within the observed range, and not in higher or lower carbohydrate intakes. With the methods applied, we were not able to distinguish between low and high glycaemic index carbohydrates. Due to this shortcoming, the results only reflect the total carbohydrate intake. It should also be noted that using the grams/day criteria ( $<130 \mathrm{~g} /$ day) for a low-carbohydrate diet, identifies not only those attempting to adhere to a low-carbohydrate diet, but also any light eaters. Women, for example, on average eat less than men. Moreover, with longer diabetes duration, emergence of various health concerns can affect dietary intake. By taking sex, diabetes duration and eGFR into account, we ensured that the two groups were comparable with regards to these basic characteristics. Finally, while the number of low-carbohydrate adherents was modest, in the current study, by using the carbohydrate-to-fat ratio we were able to include the whole population in the analyses, and to see whether the relative distribution of the two macronutrients played any role in the health markers.

In conclusion, lower carbohydrate intake and lower dietary carbohydrate-to-fat ratio were associated with a number of beneficial metabolic observations, such as lower variability in the blood glucose concentrations, lower blood pressure, and higher HDL-cholesterol concentration. However, in men adherence to low-carbohydrate diet was associated with higher total and non-HDL cholesterol concentrations, and higher waist-to-hip ratio. Large randomized controlled trials are needed to reveal the long-term risks and benefits of low-carbohydrate diets in type 1 diabetes.

\section{Acknowledgements}

This study was supported by grants from Academy of Finland (grant number 316664); Novo Nordisk Foundation (\#NNF14SA0003); Signe and Ane Gyllenberg Foundation; Folkhälsan Research Foundation; Helsinki University Central Hospital Research Funds; Wilhelm and Else Stockmann Foundation; Liv och Hälsa Society, Finland; and Päivikki and Sakari Sohlberg Foundation. Funding agencies did not contribute to the study design, conduct of the study, analysis of samples or data, interpretation of the findings, writing of the manuscript, or in the decision to submit the manuscript for publication. The skilled technical assistance of Anna Sandelin, Mira Korolainen, and Jaana Tuomikangas is gratefully acknowledged. The authors also acknowledge all the physicians and nurses at each centre participating in the collection of patients (Supplementary material).

\section{Authorship}

All authors took part in designing the study. A.J.A. analysed the data, and wrote the first draft of the paper. A.J.A. and P.-H.G. had the primary responsibility for the final content. All authors have contributed to the writing and approved the final manuscript.

\section{Declaration of Competing Interest}

Professor Per-Henrik Groop has received grants from Eli Lilly and Roche, is an advisory board member for AbbVie, Astellas, Astra Zeneca, Boehringer-Ingelheim, Cebix, Eli Lilly, Janssen, MSD, Medscape, Mundipharma, Novartis, Novo Nordisk, and Sanofi. He has received lecture honoraria from Astellas, Astra Zeneca, Boehringer-Ingelheim, Eli Lilly, Elo Water, Genzyme, MSD, Mundipharma, Novartis, Novo Nordisk, PeerVoice, and Sanofi. All other authors declare no conflicts of interest.

\section{Appendix A. Supplementary material}

Supplementary data to this article can be found online at https://doi.org/10.1016/j.diabres.2019.107818.

\section{R E F E R E N C E S}

[1] Westman EC, Yancy Jr WS, Humphreys M. Dietary treatment of diabetes mellitus in the preinsulin era (1914-1922). Perpect Biol Med 2006;49:77-83.

[2] American Diabetes Association. 4. Lifestyle Management: Standards of Medical Care in Diabetes-2018. Diabetes Care 2018; 41(Suppl.1): p. S38-S50.

[3] Evert AB, Boucher JL, Cypress M, Dunbar SA, Franz MJ, MayerDavis EJ, et al. Nutrition therapy recommendations for the management of adults with diabetes. Diabetes Care 2014;37 (Suppl. 1):S120-43. 
[4] Ahola AJ, Mikkilä V, Mäkimattila S, Forsblom C, Freese R, Groop PH. Energy and nutrient intakes and adherence to dietary guidelines among Finnish adults with type 1 diabetes. Ann Med 2012;44:73-81.

[5] Rohlfing CL, Wiedmeyer HM, Little RR, England JD, Tennill A, Goldstein DE. Defining the relationship between plasma glucose and $\mathrm{HbA}(1 \mathrm{c})$ : analysis of glucose profiles and $\mathrm{HbA}(1 \mathrm{c})$ in the Diabetes Control and Complications Trial. Diabetes Care 2002;25:275-8.

[6] Ceriello A, Hanefeld M, Leiter L, Monnier L, Moses A, Owens D, et al. Postprandial glucose regulation and diabetic complications. Arch Intern Med 2004;164:2090-5.

[7] DAFNE Study Group. Training in flexible, intensive insulin management to enable dietary freedom in people with type 1 diabetes: dose adjustment for normal eating (DAFNE) randomised controlled trial. BMJ 2002; 325: p. 746.

[8] Brazeau AS, Mircescu H, Desjardins K, Leroux C, Strychar I, Ekoé JM, et al. Carbohydrate counting accuracy and blood glucose variability in adults with type 1 diabetes. Diabetes Res Clin Pract 2013;99:19-23.

[9] Heinemann L. Variability of insulin absorption and insulin action. Diabetes Technol Ther 2002;4:673-82.

[10] Ahola AJ, Mäkimattila S, Saraheimo M, Mikkilä V, Forsblom C, Freese R, et al. Many patients with Type 1 diabetes estimate their prandial insulin need inappropriately. J Diabetes 2010;2:194-202.

[11] McKnight JA, Wild SH, Lamb MJ, Cooper MN, Jones TW, Davis EA, et al. Glycaemic control of Type 1 diabetes in clinical practice early in the 21st century: an international comparison. Diabet Med 2015;32:1036-50.

[12] Meng Y, Bai H, Wang S, Li Z, Wang Q Chen L. Efficacy of low carbohydrate diet for type 2 diabetes mellitus management: A systematic review and meta-analysis of randomized controlled trials. Diabetes Res Clin Pract 2017;131:124-31.

[13] The Diabetes Control and Complications Trial Research Group. Hypoglycemia in the Diabetes Control and Complications Trial. Diabetes 1997; 46: p. 271-286.

[14] Lennerz BS, Barton A, Bernstein RK, Dikeman RD, Diulus C, Hallberg S, et al. Management of Type 1 Diabetes With a Very Low-Carbohydrate Diet. Pediatrics 2018;141:e20173349.

[15] Ranjan A, Schmidt S, Damm-Frydenberg C, Holst JJ, Madsbad S, Nørgaard K. Short-term effects of a low carbohydrate diet on glycaemic variables and cardiovascular risk markers in patients with type 1 diabetes: A randomized open-label crossover trial. Diabetes Obes Metab 2017;19:1479-84.

[16] Eiswirth M, Clark E, Diamond M. Low carbohydrate diet and improved glycaemic control in a patient with type one diabetes. Endocrinol Diabetes Metab Case Rep 2018. 180002.

[17] Feinman RD, Pogozelski WK, Astrup A, Bernstein RK, Fine EJ, Westman EC, et al. Dietary carbohydrate restriction as the first approach in diabetes management: critical review and evidence base. Nutrition 2015;31:1-13.

[18] FAO/WHO/UNU Expert Consultation. 2. Energy and protein requirements - some unifying concepts. World Health Organization Technical Report Series 724. 1985. http:// www.fao.org/docrep/003/aa040e/AA040E02.htm [accessed June 2019].
[19] Lawton J, Rankin D, Cooke DD, Clark M, Elliot J, Heller S. Dose Adjustment for Normal Eating: a qualitative longitudinal exploration of the food and eating practices of type 1 diabetes patients converted to flexible intensive insulin therapy in the UK. Diabetes Res Clin Pract 2011;91:87-93.

[20] Blackburn GL, Phillips JC, Morreale S. Physician's guide to popular low-carbohydrate weight-loss diets. Cleve Clin J Med 2001; 68: 761,765-6,768-9,773-4.

[21] Leow ZZX, Guelfi KJ, Davis EA, Jones TW, Fournier PA. The glycaemic benefits of a very-low-carbohydrate ketogenic diet in adults with Type 1 diabetes mellitus may be opposed by increased hypoglycaemia risk and dyslipidaemia. Diabet Med 2018;35:1258-63.

[22] Ahola AJ, Thorn LM, Saraheimo M, Forsblom C, Groop PH. Depression is associated with the metabolic syndrome among patients with type 1 diabetes. Ann Med 2010;42:495-501.

[23] Levey AS, Stevens LA, Schmid CH, Zhang YL, Castro 3rd AF, Feldman HI, et al. A new equation to estimate glomerular filtration rate. Ann Intern Med 2009;150:604-12.

[24] Wadén J, Tikkanen H, Forsblom C, Fagerudd J, PetterssonFernholm K, Lakka T, et al. Leisure time physical activity is associated with poor glycemic control in type 1 diabetic women: the FinnDiane study. Diabetes Care 2005;28:777-82.

[25] Ahola AJ, Lassenius MI, Forsblom C, Harjutsalo V, Lehto M, Groop PH. Dietary patterns reflecting healthy food choices are associated with lower serum LPS activity. Sci Rep 2017;7:6511.

[26] Nielsen JV, Gando C, Joensson E, Paulsson C. Low carbohydrate diet in type 1 diabetes, long-term improvement and adherence: A clinical audit. Diabetol Metab Syndr 2012;4:23.

[27] Krebs JD, Parry Strong A, Cresswell P, Reynolds AN, Hanna A, Haeusler S. A randomised trial of the feasibility of a low carbohydrate diet vs standard carbohydrate counting in adults with type 1 diabetes taking body weight into account. Asia Pac J Clin Nutr 2016;25:78-84.

[28] Mansoor N, Vinknes KJ, Veierød MB, Retterstøl K. Effects of low-carbohydrate diets $\mathrm{v}$. low-fat diets on body weight and cardiovascular risk factors: a meta-analysis of randomised controlled trials. Br J Nutr 2016;115:466-79.

[29] Kovatchev B, Cobelli C. Glucose Variability: Timing, Risk Analysis, and Relationship to Hypoglycemia in Diabetes. Diabetes Care 2016;39:502-10.

[30] Hirsch IB, Brownlee M. Should minimal blood glucose variability become the gold standard of glycemic control?. J Diabetes Complications 2005;19:178-81.

[31] Bueno NB, de Melo IS, de Oliveira SL, da Rocha Ataide T. Verylow-carbohydrate ketogenic diet v. low-fat diet for long-term weight loss: a meta-analysis of randomised controlled trials. Br J Nutr 2013;110:1178-87.

[32] Berneis KK, Krauss RM. Metabolic origins and clinical significance of LDL heterogeneity. J Lipid Res 2002;43:1363-79.

[33] Guay V, Lamarche B, Charest A, Tremblay AJ, Couture P. Effect of short-term low- and high-fat diets on low-density lipoprotein particle size in normolipidemic subjects. Metabolism 2012;61:76-83. 